\title{
Skin status for predicting pressure ulcer development: A systematic review and meta-analyses
}

DOI:

10.1016/j.jinurstu.2018.07.003

\section{Document Version}

Accepted author manuscript

Link to publication record in Manchester Research Explorer

\section{Citation for published version (APA):}

Shi, C., Dumville, J. C., \& Cullum, N. (2018). Skin status for predicting pressure ulcer development: A systematic review and meta-analyses. International Journal of Nursing Studies, 87, 14-25.

https://doi.org/10.1016/j.jinurstu.2018.07.003

\section{Published in:}

International Journal of Nursing Studies

\section{Citing this paper}

Please note that where the full-text provided on Manchester Research Explorer is the Author Accepted Manuscript or Proof version this may differ from the final Published version. If citing, it is advised that you check and use the publisher's definitive version.

\section{General rights}

Copyright and moral rights for the publications made accessible in the Research Explorer are retained by the authors and/or other copyright owners and it is a condition of accessing publications that users recognise and abide by the legal requirements associated with these rights.

\section{Takedown policy}

If you believe that this document breaches copyright please refer to the University of Manchester's Takedown Procedures [http://man.ac.uk/04Y6Bo] or contact uml.scholarlycommunications@manchester.ac.uk providing relevant details, so we can investigate your claim.

\section{OPEN ACCESS}




\section{Accepted Manuscript}

Title: Skin status for predicting pressure ulcer development: a systematic review and meta-analyses

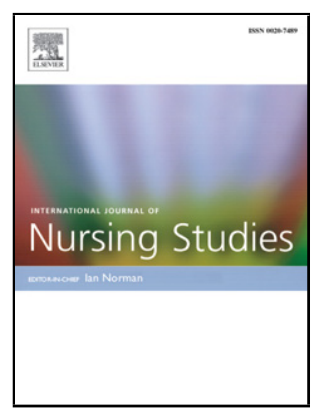

Authors: Chunhu Shi, Jo C. Dumville, Nicky Cullum

PII: $\quad$ S0020-7489(18)30155-X

DOI: $\quad$ https://doi.org/10.1016/j.ijnurstu.2018.07.003

Reference: $\quad$ NS 3181

To appear in:

Received date: $\quad$ 12-4-2018

Revised date: $\quad$ 15-6-2018

Accepted date: 2-7-2018

Please cite this article as: Shi C, Dumville JC, Cullum N, Skin status for predicting pressure ulcer development: a systematic review and meta-analyses, International Journal of Nursing Studies (2018), https://doi.org/10.1016/j.ijnurstu.2018.07.003

This is a PDF file of an unedited manuscript that has been accepted for publication. As a service to our customers we are providing this early version of the manuscript. The manuscript will undergo copyediting, typesetting, and review of the resulting proof before it is published in its final form. Please note that during the production process errors may be discovered which could affect the content, and all legal disclaimers that apply to the journal pertain. 


\title{
Skin status for predicting pressure ulcer development: a systematic review and meta-analyses
}

Chunhu Shi ${ }^{1 *}$, Jo C Dumville ${ }^{1}$, Nicky Cullum ${ }^{1,2}$

1 Division of Nursing, Midwifery \& Social Work, School of Health Sciences, Faculty of Biology, Medicine \& Health, University of Manchester, Manchester Academic Health Science Centre, Manchester, UK, M13 9PL

2 Research and Innovation Division, Manchester University NHS Foundation Trust, Manchester Academic Health Science Centre, 1st Floor, Nowgen Building, 29 Grafton Street, Manchester, UK, M13 9WU

* Corresponding author

Mobile: 44(0)7421239138

E-mail: chunhu.shi@ postgrad.manchester.ac.uk; shichunhu2014@ hotmail.com (CS)

\begin{abstract}
Background: People with altered skin status are conventionally considered to have a higher risk of developing new ulcers. However, the evidence underpinning this potentially prognostic relationship is unclear.
\end{abstract}

Objectives: To systematically review the evidence for the prognostic association of skin status with pressure ulcer risk.

Methods: We performed a comprehensive electronic database search in February 2017 to identify longitudinal studies that considered skin status in multivariable analysis for predicting pressure ulcer 
risk in any population. Study selection was conducted by two reviewers independently. We collected data on the characteristics of studies, participants, skin status, and results of multivariable analyses of skin status-pressure ulcer incidence associations. We applied the Quality In Prognosis Studies tool to assess risk of bias. We conducted meta-analyses using STATA where data were available from multivariable analyses. We used the Grades of Recommendation Assessment, Development and Evaluation approach to assess the certainty of evidence generated from each meta-analysis.

Results: We included 41 studies (with 162,299 participants, and 7,382 having new ulcers) that investigated 15 skin descriptors. Participants were predominantly hospitalised adults and long-term care residents (with a median age of 75.2 years). Studies had a median follow-up duration of 7.5 weeks. 61.0\% (25/41) of studies were judged as being high risk of bias. 53.7\% (22/41) of studies had small sample sizes. Subsequently, the certainty of evidence was rated as low or very low for all 13 meta-analyses that we conducted though all analyses showed statistically significant associations of specific skin descriptors-pressure ulcer incidence. People with non-blanchable erythema may have higher odds of developing pressure ulcers than those without (Odds Ratio $=3.08$, 95\% Confidence Interval 2.26 to 4.20 if pressure ulcer preventive measures were not adjusted in multivariable analysis; $1.99,1.76$ to 2.25 if adjusted) (both low-certainty evidence). The evidence for other skin descriptors was judged as very low-certainty and their prognostic value is uncertain.

\section{Conclusions:}

There is low-certainty evidence that people with non-blanchable erythema may be more likely to develop new pressure ulcers than those without non-blanchable erythema. The evidence for the prognostic effects of other skin descriptors (e.g., history of pressure ulcer) is of very low-certainty. The findings support regular skin assessment and preventive action being taken in the presence of non-blanchable erythema. Given the millions at risk of ulceration and the widely recommended use of skin status as part of risk assessment there is a need for more, high quality confirmatory studies.

Keywords : Pressure Ulcer, Systematic Review, Meta-Analysis, Prognostic Factor, Skin status 


\section{What is already known about the topic?}

- Skin assessments by eye and touch are routinely carried out for pressure ulcer prevention to check for abnormalities (e.g., non-blanchable erythema), and people with such skin abnormalities are often considered to be at a particularly high risk of developing new ulcers.

- Guidelines recommend that nurses should increase the provision of preventive interventions (e.g., specific support surfaces) in the presence of non-blanching erythema.

- Three previous systematic reviews summarising the evidence for skin status signalling increased pressure ulcer risk have methodological limitations (e.g., not appropriately assessing risk of bias in included studies).

\section{What this paper adds}

- This prognostic factor systematic review includes thirteen meta-analyses of data for corresponding skin status descriptors and identifies their prognostic value in pressure ulcer development.

- There is no high-certainty evidence that any of the 15 skin descriptors are strong predictors of the risk of new pressure ulcer development. People with non-blanchable erythema may be more likely to develop new pressure ulcers than those without however this evidence is low certainty.

- High-quality, confirmatory prognosis research and individual participant data meta-analysis are needed to improve the evidence base. 


\section{Introduction}

Pressure ulcers (also known as pressure injuries, pressure sores, bedsores, and decubitus ulcers) are localised injuries to skin and/or underlying tissue, caused by pressure, shear or both (NPUAP/EPUAP/PPPIA 2014). Pressure ulcers represent a serious health burden, with a point prevalence of approximately 3.1 per 10,000 in the geographical population of the city of Leeds, United Kingdom (Cullum et al., 2016) whilst hospital prevalence estimates range from 470 to 3,210 per 10,000 patients in the United Kingdom, United States and Canada (Kaltenthaler et al., 2001).

For people at pressure ulcer risk, guidelines recommend that care practitioners should carry out regular, comprehensive skin assessments to identify any abnormal changes in the appearance or texture of skin, in particular over bony prominences (NICE, 2014). Possible abnormalities include changes of skin integrity (e.g., current pressure ulcers), colour changes (e.g., non-blanchable erythema), and/or variations in moisture (e.g., moist skin, oedematous or dry skin) (NICE, 2014). People with such skin status are often regarded as having a particularly high risk of developing new ulcers (NPUAP/EPUAP/PPPIA 2014) so monitoring for their presence is deemed important in developing individualised skin care planning. For example, guidelines recommend that when people have non-blanchable erythema care practitioners should start the provision of appropriate preventive interventions (e.g., specific support surfaces) to deter the progression of developing a severe pressure ulcer (Vanderwee et al., 2007).

Given the importance of skin assessment in pressure ulcer management it is crucial to investigate evidence on the predictive value of specific skin status descriptors. That is, the evidence on whether people with certain skin status have a higher risk of developing a new pressure ulcer than those without. Currently, three systematic reviews suggest that skin status (e.g., non-blanchable erythema) is significantly associated with pressure ulcer development in general populations (Coleman et al., 2013; Marin et al., 2013; Michel et al., 2012). However, none of these reviews followed the currently recommended methods for prognosis systematic reviews (Riley et al., 2007) and could be significantly improved by using more sensitive search strategies, using appropriate tools for risk of bias assessment, integrating bias considerations in the synthesis, and quantifying the strength of prognostic association of skin status.

\section{Objectives}

To assess the independent prognostic value of a variety of skin status descriptors in predicting pressure ulcer development. 


\section{Methods}

This review was based on recent methods developments in the design and conduct of prognosis systematic reviews proposed by the Cochrane Prognosis Methods Group (Riley et al., 2007). It was registered with PROSPERO (CRD42016042140) and complies with the Meta-analyses Of Observational Studies in Epidemiology statement for its reporting (Stroup et al., 2000).

\subsection{Eligibility crite ria}

We included longitudinal studies that considered skin status descriptors in multivariable analyses for predicting pressure ulcer risk in any population (Steyerberg et al., 2013). Eligible studies measured pressure ulcer incidence or the time to a new ulcer as outcomes, with individuals as the unit of analysis. We included studies irrespective of whether they reported pressure ulcer outcomes as: Grade 1 or above ulcer incidence; Grade 2 or above ulcer incidence or both. Where studies did report multiple incidence outcomes, sensitivity analysis was conducted (see below).

In terms of defining what counted as a skin status descriptor we considered three key categories: colour changes (e.g., non-blanchable erythema); variations in moisture (e.g., moist skin, dry skin); and changes of skin integrity (e.g., current pressure ulcers, previous pressure ulcers) (Coleman et al., 2013). However, we did not restrict study inclusion on specific skin statuses within these categories. Rather, we considered any skin status that was investigated in studies as eligible if it could be determined by eye and touch in practice. We included studies regardless of whether they targeted a specific skin status to evaluate its independent effect (confirmatory phase study), or aimed to explore a group of potential prognostic factors that included a specific skin status (exploratory phase study) (Hayden et al., 2008).

We excluded case-control studies, cross-sectional studies, case series, case reports, reviews, qualitative studies, comments, and animal studies (Steyerberg et al., 2013). We also excluded studies of participants undergoing flap coverage of pressure ulcers, as well as studies focusing on medical device-related ulcers.

\subsection{Search strategy}

We developed search strategies that combined the pressure ulcer terms used by Cochrane Wounds (McInnes et al., 2015) with published prognosis study search filters. Prognostic study search filters from Ingui and Rogers (2001) and Geersing et al. (2012) were used with pressure ulcer terms to search Ovid MEDLINE (1946 to 14 February 2017) (see Appendix 1). The prognosis study filter from Walker-Dilks et al. (2008) was used with pressure ulcer terms to search EBSCO CINAHL Plus (1937 to 14 February 2017). All these search strategies had been validated. There was no restriction on the basis of language or publication status. 
We also searched ProQuest (14 February 2017) for relevant doctoral theses in English and Chinese using the filter detailed in Wilczynski and Haynes (2004). We checked the reference lists of eight relevant systematic reviews (Beeckman et al., 2014, Coleman et al., 2013, Gélis et al., 2009, Ham et al., 2014, Liu et al., 2012, Marin et al., 2013, Michel et al., 2012, Reenalda et al., 2009) and of the included studies for any potentially relevant entries. We also contacted the original investigators of the included studies for any relevant entries.

\subsection{Study selection}

One reviewer screened the titles and abstracts of all citations returned from the search. To support the second screening of the large number of records in a timely way, all citations were divided into six batches and each batch independently screened by a different second reviewer. Disagreements were resolved by discussion between the two reviewers and involvement of a third reviewer if necessary. One reviewer inspected the full texts of all potentially eligible studies and a second reviewer independently judged the eligibility of $10 \%$ of the potentially eligible studies, which we selected at random. Again, disagreements were resolved by discussion between the two reviewers and involvement of a third reviewer if necessary.

\subsection{Data Extraction}

One reviewer extracted data for all the included studies using a pre-specified data extraction form. A second reviewer checked the data of a randomly selected $20 \%$ of studies. Any disagreements were resolved by discussion, and if necessary with the involvement of a third reviewer. Where necessary, the authors of the included studies were contacted to request missing data.

We designed the data extraction form based on REporting recommendations for tumour MARKer prognostic studies (McShane et al., 2005; Altman et al., 2012), and relevant methodological guides (Altman and Lyman, 1998; Hayden et al., 2006; Peat et al., 2014; Riley et al., 2003). The form comprised: general information about studies, study settings, study design (involving a judgement of whether the investigation was exploratory or confirmatory), participants (sample size, age, gender, baseline skin status and risk of pressure ulcer development), skin status (definition, measurement, cutoff value), confounders and other factors that were adjusted in multivariable analysis, outcomes (definitions and events), follow-up duration, multivariable analysis methods, prognostic association measures and summary statistics. Here we defined three confounders: age, baseline risk of pressure ulcer development and use of pressure ulcer preventive measures (such measures being interventions that would be related to both any skin status and pressure ulcer incidence) (Schoonhoven et al., 2002).

We extracted adjusted odds ratios (ORs) and standard errors (SEs) (or 95\% confidence intervals (CIs)) for binary outcome, as well as adjusted hazard ratios (HRs) and standard errors (SEs) (or 95\% 
CIs) for time-to-event outcomes. Where possible, we also extracted related data and transformed them into the appropriate format: $\mathrm{P}$ values (converted to SEs); relative risks (RRs) (converted to ORs) (Higgins and Green, 2011); and observed number of events and log-rank test chi-square statistic (converted to HRs and SEs) (Parmar et al., 1998). Sensitivity analyses were conducted to investigate the impact of these data transformation on meta-analyses outputs.

\subsection{Risk of bias assessment}

One reviewer applied the Quality In Prognosis Studies tool to assess risk of bias for each included study (Hayden et al., 2013). Risk of bias was judged as low, unclear or high for each of six domains: study participation, study attrition, prognostic factor measurement, outcome measurement, study confounding, and statistical analysis and reporting. A second reviewer checked a randomly selected $20 \%$ of studies. Any discrepancy between two reviewers was resolved by discussion and a third reviewer was involved where necessary.

\subsection{Data synthesis}

We narratively summarised key baseline characteristics of included studies: study design, setting, participants, outcome definitions, follow-up durations, skin status, and confounders. We tabulated recorded skin status in order to record the breadth of skin status that were investigated in included studies.

For studies with data for meta-analysis, we used the generic inverse variance meta-analysis to pool aggregate, study-level data for each of included skin status descriptors (Higgins and Green, 2011). We used the primary outcome of each study as the data to be included in the meta-analysis. Where a study had multiple outcomes, we undertook sensitivity analyses (see below). We report ORs and 95\% CIs for binary data and HRs and 95\% CIs for time-to-event data. We used a fixed-effect model if included studies were homogeneous for settings, participants, outcome definitions, the sets of factors to be adjusted for and follow-up durations; otherwise, we used a random-effects model to estimate the average prognostic effects (Altman, 2001). We analysed binary and time-to-event data separately for each skin status. We used STATA (Version 14.0, StataCorp, College Station, Texas) for all analyses and presented pooled results in forest plots.

We used the Grades of Recommendation Assessment, Development and Evaluation approach proposed by Huguet et al. (2013) to assess the certainty of evidence from each meta-analysis: considering six factors to downgrade the certainty (phase of investigation, study limitations, inconsistency, indirectness, imprecision, and publication bias) as well as using two factors (moderate or large effect size, and exposure-response gradient) to upgrade the certainty. We presented evidence in a summary of findings table. 
For studies without data for a meta-analysis of effect sizes, we used the sign test to judge the existence of prognostic association (Borenstein et al., 2009). In sign tests, we counted the number of studies with associations in one direction (i.e., point estimate falls in one side of non-effect) and compared this with the number of studies with associations in another direction (Borenstein et al., 2009). The sign test is a valid non-parametric analysis method and does not consider whether or not associations are statistically significant (and so is different from the vote-counting method). In the sign test, if the direction of half the included studies lay on each side of the null, we considered there was no clear evidence of a prognostic association (Borenstein et al., 2009). We also checked the consistency between the findings of a sign test and meta-analysis for specific skin status descriptors.

\subsubsection{Investigation of hete rogeneity}

We assessed clinical and methodological heterogeneity by comparing settings, participants, skin assessment methods, outcome definitions, the sets of factors (including confounders) to be adjusted for, and follow-up durations across studies of a meta-analysis. We evaluated statistical heterogeneity by measuring the $\mathrm{I}^{2}$ (Higgins et al., 2003). The heterogeneity was considered as low, moderate, or high if $\mathrm{I}^{2}$ less than $25 \%, 25 \%$ to $75 \%$, or more than $75 \%$, respectively (Higgins et al., 2003). Where moderate or high heterogeneity existed, we aimed to explain it using pre-specified sub-group analyses as below.

\subsubsection{Sub-group analysis}

To try and explain heterogeneity, we pre-specified two sub-group analyses including the anticipated direction of the sub-group effect (Sun et al., 2010). The first sub-group analysis explored modification of findings based on whether data were from an exploratory or confirmatory phase study (termed investigation phase sub-group analysis hereafter); with the assumption that the effect of confirmatory studies would be smaller and more precise than that of exploratory studies (Hayden et al., 2008). The second sub-group analysis explored findings between studies with and without adjustment for pressure ulcer preventive measures (termed adjustment sub-group analysis hereafter); assuming that preventive measures would result in negative confounding in the skin status-pressure ulcer incidence association (Mehio-Sibai et al., 2005) and therefore the effect of studies adjusted for preventive measures would be larger than that of studies without adjustment. We applied the method described by Altman and Bland (2003) to test whether effect difference between sub-groups was significant (i.e., tests for interaction).

\subsubsection{Sensitivity analys is}

Sensitivity analyses were conducted for two pre-specified factors to explore: (1) the impact of removing studies at high risk of attrition bias; and (2) the impact of removing studies which used 
transformed data. A third post-hoc analysis was conducted to explore the impact of including the reported secondary outcome rather than primary outcome if a study reported multiple outcomes.

\subsubsection{Publication bias assessment}

We assessed the potential for publication bias by considering the completeness of the literature search, checking whether all included studies completely presented data, and plotting contourenhanced funnel plots for meta-analyses that included more than 10 studies (Peters et al., 2008).

\section{Results}

\subsection{Search results}

We retrieved 6,908 records through electronic searching and other resources. Full-text screening of 561 potentially relevant studies led to the inclusion of 41 studies (with 50 publications) (see Fig. 1Allegretti, 2008; Allman et al., 1995; Anthony et al., 2000, 2003; Baumgarten et al., 2004, 2006, 2009; Bergquist-Beringer and Gajewski, 2011; Berlowitz et al., 1996, 2001a, 2001b; Compton et al., 2008; de Groot et al., 2006; de Souza and Santos, 2007; Defloor and Grypdonck, 2005; DeJong et al., 2014; Demarré et al., 2012, 2015; Gordon, 2009; Horn et al., 2002, 2004; Kroll et al., 2007; Man and Au-Yeung, 2013; Magaziner et al., 2000; Molon and Estrella, 2011; Nixon et al., 2006a, 2006b, 2007, 2015; Page et al., 2011; Papanikolaou et al., 2002; Perneger et al., 2002; Poss et al., 2010; Primiano et al., 2011; Reed et al., 2003; Rich et al., 2011; Scheel-Sailer et al., 2013; Schnelle et al., 1997; Schoonhoven et al., 2005, 2006, 2007; Smith et al., 2017; Stordeur et al., 1998; Takahashi et al., 2011; Tsai et al., 2012; Vanderwee et al., 2005, 2007; van der Wielen; 2016; Verschueren et al., 2011; Webster et al, 2011). Of the 41 studies, two (4.94\%) were studies with theses as publications (Allegretti, 2008; Gordon, 2009). 

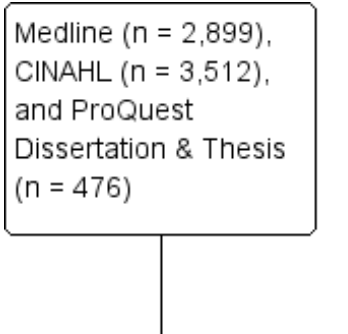

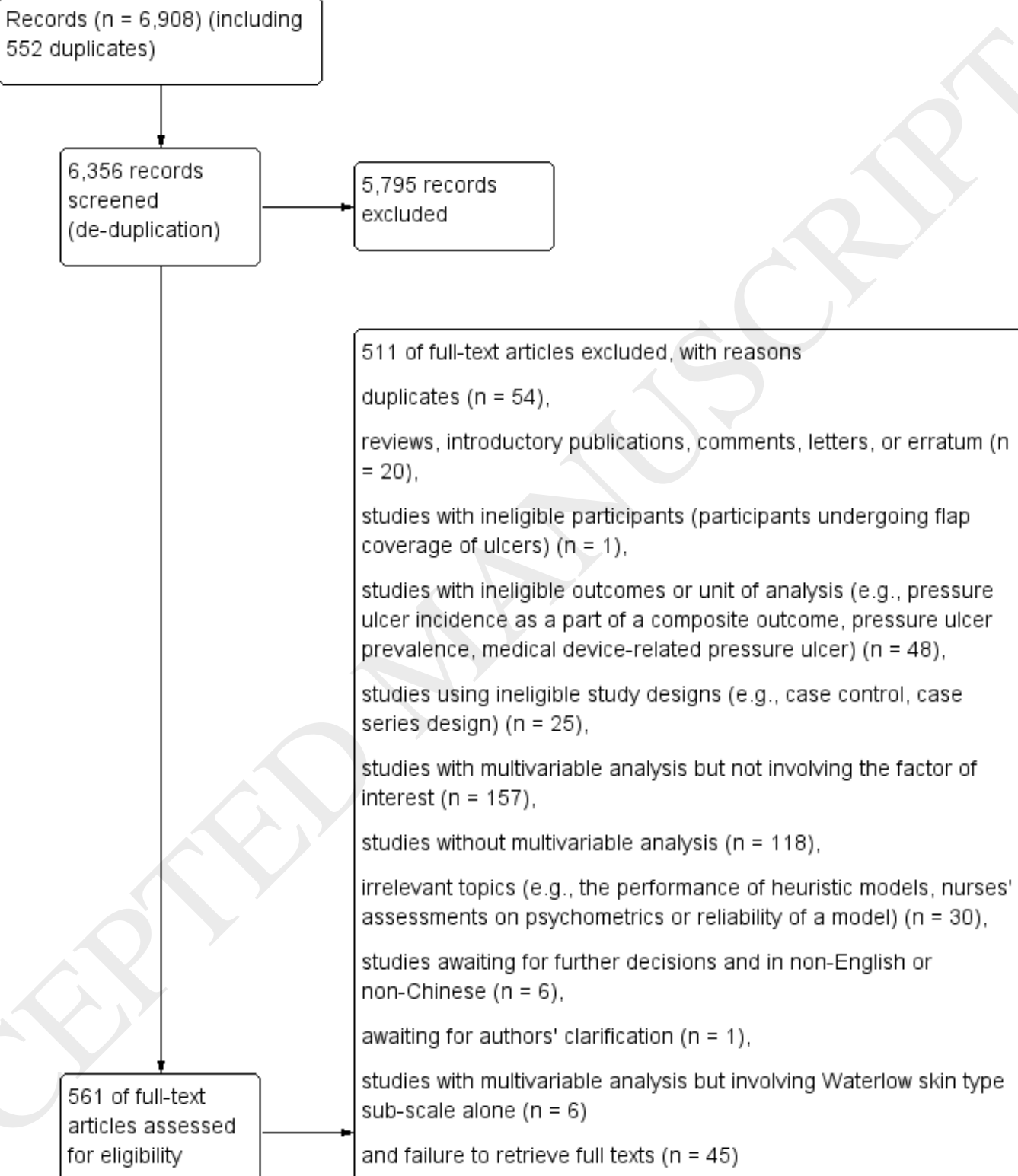

511 of full-text articles excluded, with reasons duplicates $(n=54)$, reviews, introductory publications, comments, letters, or erratum (n $=20$ ),

studies with ineligible participants (participants undergoing flap coverage of ulcers) $(n=1)$,

studies with ineligible outcomes or unit of analysis (e.g., pressure ulcer incidence as a part of a composite outcome, pressure ulcer prevalence, medical device-related pressure ulcer) $(n=48)$,

studies using ineligible study designs (e.g., case control, case series design) $(n=25)$,

studies with multivariable analysis but not involving the factor of interest ( $n=157$ ),

studies without multivariable analysis $(n=118)$,

irrelevant topics (e.g., the performance of heuristic models, nurses' assessments on psychometrics or reliability of a model) $(n=30)$,

studies awaiting for further decisions and in non-English or non-Chinese $(n=6)$,

awaiting for authors' clarification $(n=1)$,

studies with multivariable analysis but involving Waterlow skin type

561 of full-text articles assessed sub-scale alone $(n=6)$

for eligibility

and failure to retrieve full texts $(n=45)$

\section{Fig. 1. Flow chart of study selection}




\subsection{Characteris tics of included studies}

See Appendix 2 for the characteristics of included studies. Of the 41 included studies, 29 (70.7\%) used a prospective design and only two (4.4\%) were confirmatory phase. The 41 studies enrolled a total of 162,299 participants (median of sample sizes: 602, range: 40 to 45,735). From the 37 studies that reported the average age of participants, the median of the averages was 75.2 (range: 7.2 to 87.3) years. The included studies were conducted in a variety of settings, with 18 (43.9\%) being in hospitals, and $12(29.3 \%)$ being in long-term care settings.

39 of the 41 studies $(95.1 \%)$ defined a single incidence outcome as: either development of: Grade 2 or higher ulcers $(\mathrm{n}=19)$; Grade 1 or higher ulcers $(\mathrm{n}=3)$; incidence of ulcers with undefined grade $(\mathrm{n}$ $=16$ ), or time to new pressure ulcer development $(\mathrm{n}=1)$. Only two studies defined multiple outcomes, both reporting incidence of ulcers of Grade 2 or higher as the primary outcome (these data were pooled with the Grade 2 or higher ulcer data in main analyses), and incidence of Grade 1 or higher ulcers as the secondary outcome (this was analysed in sensitivity analyses). Thirty of the 41 studies $(73.2 \%)$ reported follow-up durations, with an overall median of 7.5 (range: 0.5 to 171.5) weeks. Of the 41 studies, $22(53.7 \%)$ had fewer than 10 events per variable indicating that sample sizes were inadequate.

The included studies investigated a total of 15 skin status descriptors (see Table 1); the three most common descriptors investigated were non-blanchable erythema (13 studies, 31.7\%), current pressure ulcers (17 studies, $41.5 \%$ ), and history of pressure ulcers (11 studies, 26.8\%). Heterogeneous methods were employed across studies for assessing each of these skin status descriptors. Ten of the 41 studies (24.4\%) considered pressure ulcer preventive measures as a confounder in the analysis for adjusting effects of these skin status descriptors. Forty of the 41 studies (97.6\%) considered specific skin status descriptors at the patient-level (rather than at the anatomical location level) in their main analyses. Of these 40 studies, Smith et al. (2017) employed a secondary analysis that explored the association of skin status and pressure ulcer development at the same location. Allman et al. (1995) was the only one study that investigated the association of sacral or coccygeal skin status with pressure ulcer development at the same location in its main analysis.

Table 1. Skin status and measurement methods

\begin{tabular}{|l|l|l|l|}
\hline Number & Skin status & Included studies & Measurement methods \\
\hline 1 & $\begin{array}{l}\text { Blanchable erythema (197, } \\
36 \text { events) }\end{array}$ & $\begin{array}{l}\text { Nixon et al. } \\
(2007)\end{array}$ & $\begin{array}{l}\text { Research nurses using visual skin } \\
\text { assessment methods }\end{array}$ \\
\hline & & $\begin{array}{l}\text { Schnelle et al. } \\
(1997)\end{array}$ & $\begin{array}{l}\text { A validated severity measurement tool } \\
\text { for assessing the severity of blanchable } \\
\text { erythema }\end{array}$ \\
\hline
\end{tabular}




\begin{tabular}{|c|c|c|c|}
\hline 2 & $\begin{array}{l}\text { Non-blanchable erythema } \\
(68,078,3,967 \text { events })\end{array}$ & $\begin{array}{l}\text { Anthony et al. } \\
(2000)\end{array}$ & $\begin{array}{l}\text { Assessing via } \text { Waterlow skin type } \\
\text { subscale }\end{array}$ \\
\hline & & $\begin{array}{lr}\text { Allman } & \text { et al. } \\
\text { (1995); Demarré } \\
\text { et al. (2015); } \\
\text { Molon } & \text { and } \\
\text { Estrella } & \text { (2011); } \\
\text { Nixon et al. } \\
\text { (2006); Nixon et } \\
\text { al. (2007); Smith } \\
\text { et al. (2017); } \\
\text { Vanderwee et al. } \\
\text { (2005); } \\
\text { Vanderwee et al. } \\
\text { (2007) }\end{array}$ & Using skin assessment \\
\hline & & $\begin{array}{l}\text { Berlowitz et al. } \\
\text { (1996); Reed et al. } \\
\text { (2003) }\end{array}$ & Reviewing medical records \\
\hline & & $\begin{array}{l}\text { Berlowitz et al. } \\
(2001 \mathrm{a}, 2001 \mathrm{~b})\end{array}$ & Not reported \\
\hline 3 & $\begin{array}{l}\text { Current presence of } \\
\text { pressure ulcers }(66,905, \\
2,717 \text { events })\end{array}$ & $\begin{array}{l}\text { Baumgarten et al. } \\
(2006, \quad 2009) ; \\
\text { Bergquist- } \\
\text { Beringer and } \\
\text { Gajewski (2011) }\end{array}$ & Using combined methods \\
\hline & & $\begin{array}{l}\text { Anthony et al. } \\
\text { (2003); DeJong et } \\
\text { al. (2014); Horn et } \\
\text { al. (2004); Man } \\
\text { and Au-Yeung } \\
\text { (2013); Perneger } \\
\text { et al. (2002); } \\
\text { Primiano et al. } \\
\text { (2011) }\end{array}$ & Collected from medical records \\
\hline & & $\begin{array}{ll}\text { Nixon } & \text { et al. } \\
(2006 a, & 2006 b) ;\end{array}$ & Using skin assessment \\
\hline
\end{tabular}




\begin{tabular}{|c|c|c|c|}
\hline & & $\begin{array}{l}\text { Scheel-Sailer et al. } \\
(2013) \text {; Stordeur } \\
\text { et al. (1998); } \\
\text { Webster et al. } \\
(2011)\end{array}$ & \\
\hline & & Kroll et al. (2007) & Self-reported by participants \\
\hline & & $\begin{array}{l}\text { Baumgarten et al. } \\
(2004) ; \quad \text { Defloor } \\
\text { and Grypdonck } \\
(2005) \text {; } \\
\text { Verschueren et al. } \\
(2011)\end{array}$ & Not reported \\
\hline \multirow[t]{4}{*}{4} & $\begin{array}{l}\text { History of pressure ulcers } \\
\text { (i.e., history of pressure } \\
\text { ulcers that previously } \\
\text { occurred at any time but } \\
\text { had been resolved prior to } \\
\text { the start of a study) } \\
(44,165,2,504 \text { events) }\end{array}$ & $\begin{array}{l}\text { Allegretti (2008); } \\
\text { Horn et al. (2004); } \\
\text { Primiano et al. } \\
\text { (2011); Takahashi } \\
\text { et al. (2011) }\end{array}$ & Collected from medical records \\
\hline & & $\begin{array}{l}\text { de Souza and } \\
\text { Santos (2007); } \\
\text { Rich et al. (2011); } \\
\text { Schoonhoven et } \\
\text { al. (2006) }\end{array}$ & Using skin assessment \\
\hline & & Tsai et al. (2012) & Self-reported by participants \\
\hline & & $\begin{array}{l}\text { Berlowitz et al. } \\
(2001 \mathrm{a}, \quad 2001 \mathrm{~b}) ; \\
\text { Poss et al. (2010) }\end{array}$ & Not reported \\
\hline 5 & $\begin{array}{l}\text { Dry skin }(3,559, \quad 246 \\
\text { events })\end{array}$ & $\begin{array}{l}\text { Baumgarten et al. } \\
(2006)\end{array}$ & Using combined methods \\
\hline & & $\begin{array}{l}\text { Allman et al. } \\
\text { (1995); Molon and } \\
\text { Estrella (2011) }\end{array}$ & Using skin assessment \\
\hline 6 & $\begin{array}{llll}\begin{array}{l}\text { Moist } \\
\text { skin }\end{array} & (698, & 121 \\
\text { events }) & & & \\
\end{array}$ & $\begin{array}{l}\text { Compton et al. } \\
(2008)\end{array}$ & Collected from medical records \\
\hline 7 & $\begin{array}{lll}\text { Oedematous } & \text { skin } \quad(698,\end{array}$ & Compton et al. & Collected from medical records \\
\hline
\end{tabular}




\begin{tabular}{|c|c|c|c|}
\hline & 121 events) & $(2008)$ & \\
\hline 8 & $\begin{array}{l}\text { Reddened skin }(698,121 \\
\text { events) }\end{array}$ & $\begin{array}{l}\text { Compton et al. } \\
(2008)\end{array}$ & Collected from medical records \\
\hline 9 & $\begin{array}{l}\text { Mottled skin }(698,121 \\
\text { events) }\end{array}$ & $\begin{array}{l}\text { Compton et al. } \\
(2008)\end{array}$ & Collected from medical records \\
\hline 10 & $\begin{array}{l}\text { Fragile skin }(342,67 \\
\text { events) }\end{array}$ & Page et al. (2011) & Using combined methods \\
\hline 11 & $\begin{array}{l}\text { Skin compromised due to } \\
\text { breaks }(342,67 \text { events) }\end{array}$ & Page et al. (2011) & Using combined methods \\
\hline \multirow[t]{2}{*}{12} & $\begin{array}{l}\text { Non-blanchable erythema } \\
\text { alone or along with other } \\
\text { skin descriptors (i.e., } \\
\text { induration, pain, warmth, } \\
\text { discolouration, oedema) } \\
\text { ( } 310,62 \text { events) }\end{array}$ & $\begin{array}{l}\text { Nixon et al. } \\
(2007)\end{array}$ & Using skin assessment \\
\hline & & $\begin{array}{l}\text { Papanikolaou et } \\
\text { al. (2002) }\end{array}$ & $\begin{array}{l}\text { Using Waterlow skin type subscale } \\
\text { (defined as Waterlow skin type (very } \\
\text { high risk) - discoloured skin alone or } \\
\text { along with other skin descriptors) }\end{array}$ \\
\hline 13 & $\begin{array}{l}\text { Broken skin alone or along } \\
\text { with other skin descriptors } \\
(213,47 \text { events })\end{array}$ & $\begin{array}{l}\text { Papanikolaou et } \\
\text { al. (2002) }\end{array}$ & $\begin{array}{l}\text { Using Waterlow skin type subscale } \\
\text { (defined as Waterlow skin type (very } \\
\text { high risk)) }\end{array}$ \\
\hline 14 & $\begin{array}{l}\text { Presence of any skin status } \\
(1,831,273 \text { events })\end{array}$ & $\begin{array}{l}\text { Schoonhoven et } \\
\text { al. (2006); Smith } \\
\text { et al. (2017) }\end{array}$ & Using skin assessment \\
\hline 15 & $\begin{array}{l}\text { History or current } \\
\text { presence of pressure ulcers } \\
(160,44 \text { events })\end{array}$ & Gordon (2009) & Using skin assessment \\
\hline
\end{tabular}

\subsection{Risk of bias assessment}

Of the 41 included studies, 25 (61.0\%) were judged as at high risk of bias for at least one domain; and only two (4.9\%) studies (Demarré et al., 2012; Nixon et al., 2006a, 2006b) were judged as low risk of bias for all six domains. The main reasons for receiving a high risk of bias judgement were: incomplete reporting of regression coefficients (e.g., negative results) in multivariable analyses, and inappropriate multivariable modelling methods/strategies (e.g., the use of stepwise selection methods to select prognostic factors in modelling which increases the risk of factor selection bias, or not correcting regression coefficients in the case of events per variable $<10$ ). See Appendix 3 for detailed reasons. 


\subsection{Meta-analysis}

To explore the association of the 15 specific skin status descriptors with pressure ulcer incidence we conducted 13 meta-analyses (see Appendix 4 for results of all meta-analyses), and all analyses showed statistically significant associations between these skin status descriptors as patient-level prognostic factors and pressure ulcer incidence. Here we only present meta-analyses for nonblanchable erythema, current presence of pressure ulcer, and history of pressure ulcer because they had the most available data for analysis (see Appendix 5 for summary of findings table).

\subsubsection{Non-blanchable erythema}

In total, 13 studies (with 68,078 participants) considered non-blanchable erythema as a factor of pressure ulcer risk, with nine studies reporting pressure ulcer incidence data (Allman et al., 1995; Berlowitz et al., 1996, 2001a, 2001b; Demarré et al., 2015; Nixon et al., 2006a, 2006b; Reed et al., 2003; Smith et al., 2017; Vanderwee et al., 2005) and one reporting time-to-event data (Vanderwee et al., 2007). The remaining three studies did not report usable data for meta-analysis and did not report the direction of associations required for a sign test (Anthony et al., 2000; Molon and Estrella, 2011; Nixon et al., 2007).

Pressure ulcer incidence data: Studies in this analysis varied in terms of study setting, outcome definition, the sets of factors adjusted for and follow-up durations. Random-effects meta-analysis showed that non-blanchable erythema was associated with increased odds of pressure ulcer development ( $n=65,902$, with 3,766 events; OR $=2.58,95 \%$ CI 2.06 to 3.24; see Fig. 2).

There was moderate statistical heterogeneity in the data $\left(I^{2}=72.1 \%\right)$. The adjustment sub-group analysis appeared to partly explain the heterogeneity: the sub-group of studies with adjustment showed a weaker association between non-blanchable erythema and pressure ulcer incidence than the sub-group of studies without adjustment (difference in two sub-group effects: ratio of ORs 1.55, 95\% CI 1.11 to 2.16; Z-statistic 2.57 , p-value 0.01 ): this was the opposite effect from that expected. No further sub-group analyses were undertaken because all studies were at the exploratory phase.

The low-certainty evidence from the sub-group of studies without adjustment suggests that if we assume 41 people per 1,000 with no non-blanchable erythema develop pressure ulcers, 116 people per 1,000 (95\% CI 87 to 151) with non-blanchable erythema would be expected to develop new ulcers (downgraded once for phase of investigation, once for study limitations, once for inconsistency, but upgraded once for moderate effect). Evidence from the sub-group of studies with adjustment is also low-certainty (downgraded once for phase of investigation and once for study limitations), suggesting that if we assume 41 per 1,000 people without non-blanchable erythema develop pressure ulcers, in comparison 78 per 1,000 (95\% CI 69 to 87) with non-blanchable erythema would be expected to 
develop new ulcers. Data were only available in sensitivity analysis for studies with data transformation, and the analysis suggests that non-blanchable erythema is still associated with pressure ulcer development.

Time-to-event data: A single study suggests that people with non-blanchable erythema may develop new pressure ulcers in a shorter time than those without (low-certainty evidence) (HR $=1.67$, 95\% CI 1.55 to $\left.1.80 ; \mathrm{I}^{2}=0.0 \%\right)$.

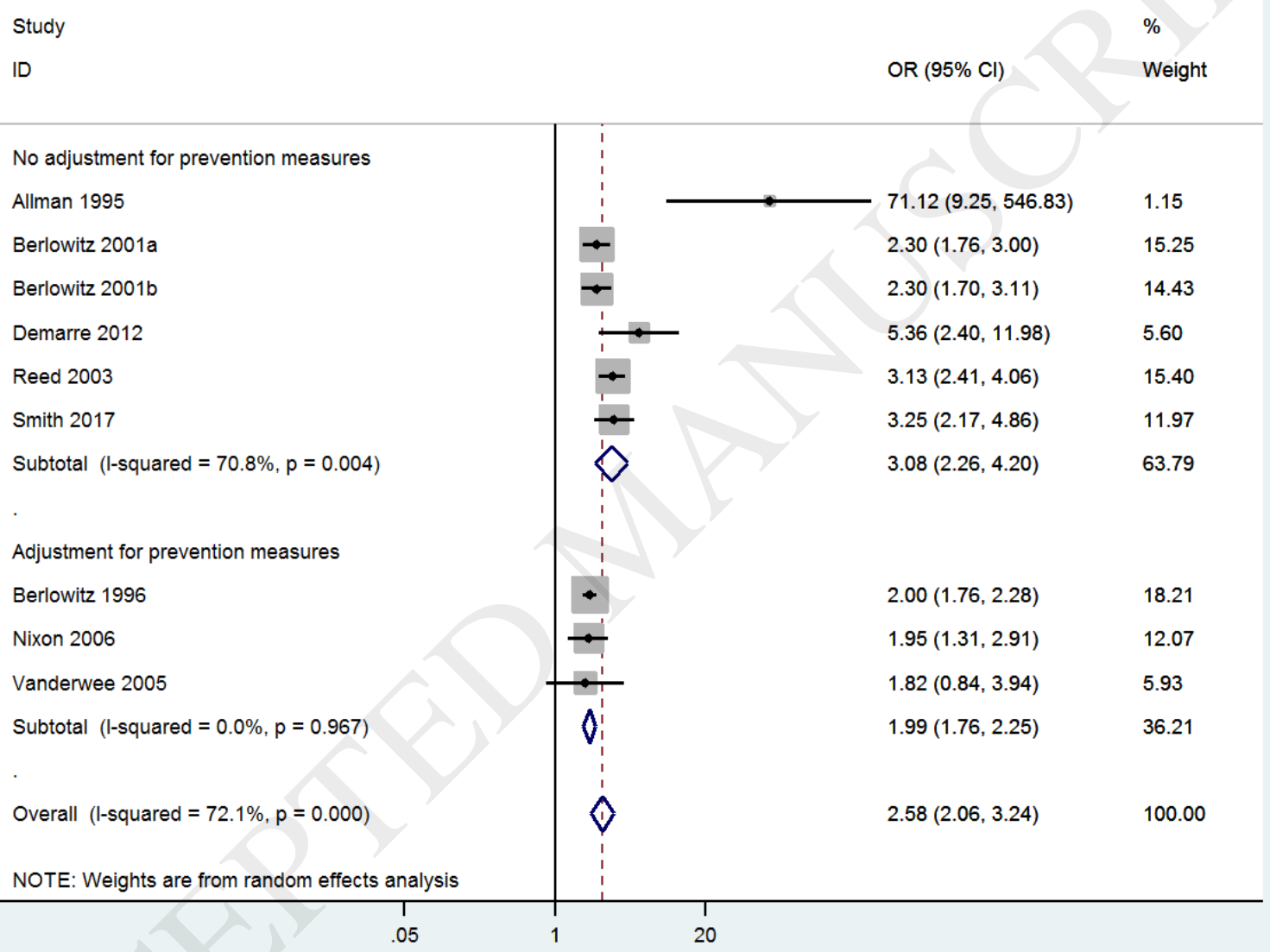

Fig. 2. Meta-analys is and adjus tment sub-group analysis exploring the as sociation between nonblanchable erythema and future pressure ulcer development

\subsubsection{Current presence of pressure ulcers}

17 studies (with 66,905 participants) considered current pressure ulcers as a risk factor for future pressure ulcer development, with 11 studies presenting pressure ulcer incidence data (Anthony et al., 2003; Bergquist-Beringer and Gajewski, 2011; Defloor and Grypdonck, 2005; DeJong et al., 2014; Kroll et al., 2007; Man and Au-Yeung, 2013; Nixon et al., 2006a, 2006b; Primiano et al., 2011; 
Scheel-Sailer et al., 2013; Verschueren et al., 2011; Webster et al., 2011), one presenting time-toevent data (Baumgarten et al., 2004). The remaining five studies did not provide data for metaanalysis or the direction of prognostic associations for a sign test (Baumgarten et al., 2006, 2009; Horn et al., 2004; Perneger et al., 2002; Stordeur et al., 1998).

Pressure ulcer incidence data: Studies in this analysis were heterogeneous regarding settings, outcome definitions, the sets of factors to be adjusted for, and follow-up durations. Random-effects meta-analysis showed a significant association between current pressure ulcers and the increased odds of future pressure ulcers (OR 2.75, 95\% CI 1.14 to 6.63; see Fig. 3).

\begin{tabular}{l} 
Study \\
ID \\
\hline No adjustment for prevention measures \\
Anthony 2003 \\
Bergquist-Beringer 2011 \\
DeJong 2014 \\
Defloor 2005 \\
Kroll 2007 \\
Man 2013 \\
Scheel-Sailer 2013 \\
Verschueren 2011 \\
Subtotal (I-squared =92.9\%, $\mathrm{p}=0.000$ ) \\
Adjustment for prevention measures
\end{tabular}

Fig. 3. Meta-analysis and the adjustment sub-group analysis exploring the association between having a current pressure ulcer and de veloping a future pressure ulcer

The analysis showed a high heterogeneity $\left(\mathrm{I}^{2}=98.0 \%\right)$. The adjustment sub-group analysis partly explained the heterogeneity (difference between sub-group effects: ratio of ORs 3.97, 95\% CI 1.73 to 9.09; p-value 0.001). The sub-group of studies without adjustment showed a significant association between current ulceration and future ulceration (OR 3.97, 95\% CI 1.73 to $9.07 ; \mathrm{I}^{2}=92.9 \%$ ) whilst there was no heterogeneity and no association between current and future pressure ulcers in the sub- 
group of studies with adjustment (OR $1.00,95 \%$ CI 0.98 to $\left.1.01 ; \mathrm{I}^{2}=0.0 \%\right)$. Evidence in both subgroups is of very low-certainty (downgraded once for phase of investigation, once for study limitations, twice for imprecision, but upgraded once for moderate effect for the sub-group of studies without adjustment; downgraded once for phase of investigation, and twice for study limitations for the sub-group of studies without adjustment), meaning that it is uncertain whether people with current pressure ulcers might be more at risk of developing new ulcers than those without.

All three planned sensitivity analyses were performed. Removal of studies at high risk of attrition bias eradicated the association between current and future pressure ulceration whilst another two sensitivity analyses had results that were consistent with the main analysis.

The main analysis had asymmetry in the contour-enhanced funnel plot indicating the presence of a small-study effect and thus a possibility of publication bias in the analysis (see Appendix 6).

Time-to-event data: The single study that reported time to pressure ulceration provided lowcertainty evidence that people with current pressure ulcers developed new pressure ulcers more quickly than those without (HR $1.80,95 \%$ CI 1.40 to 2.32 ).

\subsubsection{History of pressure ulcer}

11 studies (with 44,165 participants) considered history of pressure ulceration as a factor in future pressure ulcer risk. Eight of the 11 studies reported pressure ulcer incidence (Allegretti, 2008; Berlowitz et al., 2001a, 2001b; de Souza and Santos, 2007; Horn et al., 2004; Poss et al., 2010; Primiano et al., 2011; Takahashi et al., 2011) whilst the remaining three had no data for meta-analysis or a sign test (Rich et al., 2011; Schoonhoven et al., 2006; Tsai et al., 2012).

Pressure ulcer incidence data: Studies in this analysis were heterogeneous regarding settings, outcome definitions, the sets of factors to be adjusted for, and follow-up durations. Random-effects meta-analysis showed that people with previous pressure ulcers had 2.59 times the odds of developing new pressure ulcers than those without (OR 2.59, 95\% CI 2.01 to 3.35; see Fig. 4). 


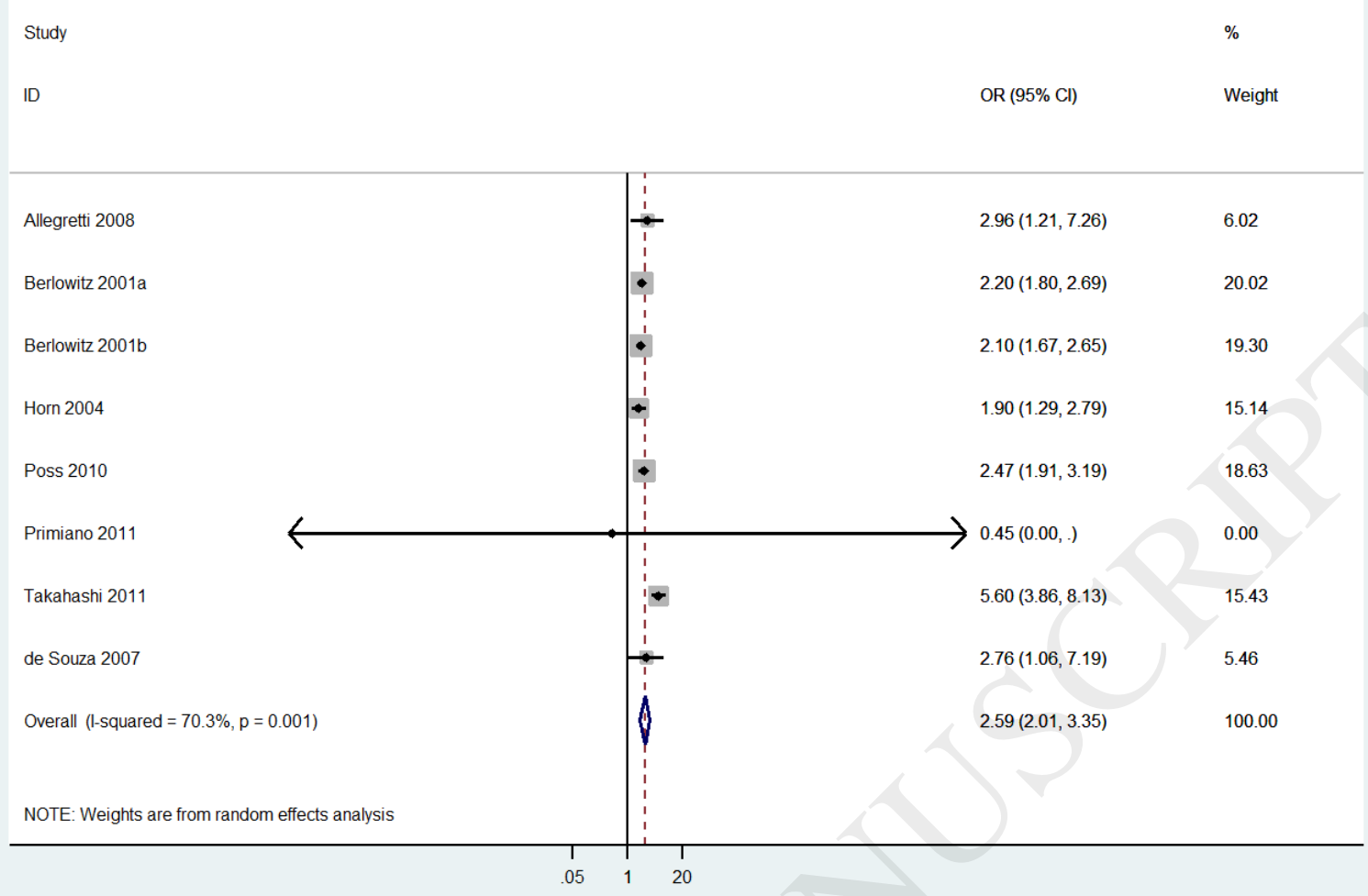

Fig. 4. Meta-analysis for the association between previous pressure ulcers and risk of new pressures

There was a moderate heterogeneity $\left(\mathrm{I}^{2}=70.3 \%\right)$; but there was no significant difference in the associations of the adjusted and non-adjusted sub-groups (ratio of ORs $0.74,95 \%$ CI 0.46 to 1.19 ; Zstatistic -1.23, p-value 0.217). Overall it is uncertain whether history of previous pressure ulceration increases the risk of future pressure ulceration (very low-certainty evidence; downgraded once for phase of investigation, twice for study limitations, once for inconsistency, but upgraded once for moderate effect).

This meta-analysis included one study with multiple outcomes (Horn et al., 2004), and the main analysis used data on ulcers of Grade 2 or higher. Sensitivity analysis using Grade 1 or higher ulcer outcome data showed a significant association (OR 2.63, 95\% CI 2.04 to 3.37; $\mathrm{I}^{2}=69.0 \%$ ), which was consistent with the main analysis. 


\section{Discussion}

\subsection{Main findings}

We have conducted the first systematic review with meta-analyses to summarise the evidence on the prognostic value of a variety of skin status descriptors that were considered as patient-level factors for predicting pressure ulcer risk. We include 41 studies with 15 skin descriptors. We found that over half of the 41 studies were judged as being at high risk of bias and they were heterogeneous in terms of settings, populations, skin assessment methods, confounders and other adjustment covariates and follow-up durations. The included studies mainly investigated the prognostic effects of nonblanchable erythema, current pressure ulcers and history of pressure ulcers with only a small number of studies exploring other changes (e.g., dry skin). Two studies sought to explore skin status at a specified location with pressure ulcer development at that location.

Meta-analyses all indicated statistically significant associations between specific skin status and subsequent pressure ulcer incidence. However, evidence for most skin status descriptors was judged to be very low-certainty using the Grades of Recommendation Assessment, Development and Evaluation approach so we cannot be certain of their prognostic value. The very low-certainty of the evidence was mainly due to the exploratory (rather than confirmatory) purpose of the existing research, serious or very serious study limitations, presence of publication bias, and unexplained heterogeneity. Nonetheless, there is low-certainty evidence that more people with non-blanchable erythema may develop new ulcers than those without; and people with non-blanchable erythema or current pressure ulcers may develop new ulcers in a shorter time than those without these factors.

\subsection{Reas ons for differences with other published studies}

Previously three reviews synthesised evidence on skin status descriptors as predictors of pressure ulcer development (Coleman et al., 2013; Marin et al., 2013; Michel et al, 2012). In terms of review questions, all previous reviews aimed to identify possible prognostic factors for future pressure ulcer development whilst our review aimed to evaluate the strength of prognostic association between skin status and pressure ulcer incidence.

The previous reviews applied rather unreliable methods and considered meta-analysis unfeasible due to heterogeneity; instead relying on vote-counting and narrative synthesis. Vote counting counts the proportion of studies that show "statistically associations" in multivariable analyses. For example, in the most rigorous and relevant review (Coleman et al., 2013), reviewers included 16 studies where skin status was considered in statistical modelling, in 12 of which skin status descriptors were significantly associated with pressure ulcer development; as a result, skin status was regarded as being prognostic. The use of vote-counting largely relies on studies with significant results and thus cannot 
fully evaluate the association of interest (Borenstein et al., 2009). Even if studies with non-significant results are considered sometimes, vote-counting often produces misleading finding (Ioannidis et al., 2008). This is because a non-significant finding in a study could mean that there is truly no association, or could indicate that the study is under-powered so that the association cannot be detected (Borenstein et al., 2009).

In our review, we used recently established prognosis review methods and considered metaanalysis as appropriate given that heterogeneity could be explained (Ioannidis et al., 2008). We evaluated the strength of prognostic associations between a range of skin status descriptors and pressure ulcer incidence. Results of our statistical analyses all suggested "significant associations" between specific skin status descriptors and pressure ulcer incidence. We also assessed how likely the finding and magnitude of associations are true using the Grades of Recommendation Assessment, Development and Evaluation approach and judged almost all the current evidence as uncertain. The previous reviews had not judged the quality (and hence certainty) of the evidence.

Additionally, previous reviews treated the included studies as all having equal strength. In line with contemporary epidemiological methodology, we considered that confirmatory phase studies provide stronger evidence than exploratory phase studies (Hayden et al., 2008). As a result, we found that confirmatory evidence on the prognostic value of skin status is still required.

This review did not set out to summarise the evidence for an association between incontinenceassociated dermatitis and pressure ulcer development as this has previously been synthesised (Beeckman et al., 2014). We did however analyse the evidence for moist skin as a prognostic factor for pressure ulceration (moist skin being the precipitating factor for incontinence-associated dermatitis).

\subsection{Exploration of sub-group findings}

The sub-group analysis that compared the results of studies with and studies without adjustment for pressure ulcer preventive measures, suggests that the association between current pressure ulcers (and non-blanchable erythema) and increased odds of new pressure ulcer development weakens when preventive measures are adjusted for. This is the opposite of what we anticipated as we assumed that preventive measures lead to negative confounding, that is, if the exposure of interest increases the odds of an outcome event, then the confounder will reduce rather than increase the odds. We expected adjustment for preventive measures to ameliorate the effects of negative confounding and strengthen the association between current pressure ulcers (or non-blanchable erythema) and ulcer risk and there are several possible explanations for why it did the opposite. Firstly the sub-group effects were from between-study comparisons rather than from a single study and thus sub-group analyses may be not credible. Secondly the significant difference in sub-group effects may be due to additional causes of 
heterogeneity such as different risks of bias. Thirdly studies adjusted for many different prevention factors and not all were confounding in the way we anticipated. Finally it is possible that those studies that did not adjust for preventive measures also did not use preventive measures for people with current pressure ulcers; if this were the case it would lead to current pressure ulceration having a stronger prognostic association in the unadjusted than in adjusted studies. All explanations could be explored further using individual participant data.

\subsection{Issues impacting on evidence quality}

The predominance of exploratory studies in this dataset is a limitation of the current evidence base. Exploratory studies tend to focus on the statistical significance of variable-event association and probably result in spurious associations (Altman and Lyman, 1998; Hayden et al., 2008).

Evidence was also downgraded due to "statistical analysis and reporting" problems with half of studies judged as being at high risk of bias for this domain. One key issue was the use of datadependent methods (e.g., the stepwise selection method) to select prognostic factors which can result in clinically important factors being removed from a model because of their statistical nonsignificance (leading to potential factor selection bias (Altman and Lyman, 1998)). A second key issue was the use of modelling on small datasets with fewer than ten events per variable $53.7 \%$ of our included studies) which could potentially result in imprecise regression coefficient results unless appropriate methods (e.g., bootstrapping) are used to adjust variables' coefficients (Altman and Lyman, 1998).

A final issue to note was the reporting of regression coefficients from statistical models - where "statistically significant" factors are more likely to be reported which can lead to potentially biased estimates from meta-analyses (Altman and Lyman, 1998). For example, four of the 13 studies considering non-blanchable erythema in the multivariable analyses did not report the coefficients for non-blanchable erythema probably because non-blanchable erythema was omitted from modelling due to lack of significance. In this situation, we cannot include all potential multivariable results of non-blanchable erythema in a meta-analysis to fully estimate its prognostic strength. Though we aimed to contact original authors to collect all potential data we failed to obtain these data to conduct a complete analysis. Future researchers should comply with reporting guidelines for observational studies to completely present modelling results (e.g., REporting recommendations for tumour MARKer prognostic studies checklist) (Altman et al., 2012; von Elm et al., 2007). We have to note that the publication bias due to the incomplete reporting of regression coefficients was considered in judging risk of bias but it was not considered again in assessing publication bias as part of the certainty of evidence assessment. 


\subsection{Strengths and limitations}

The main strengths of our review are its comprehensiveness and the application of methods for prognosis systematic reviews (Riley et al., 2007). We used validated prognosis study search filters to secure a comprehensive literature search. As a result, we identified and included 41 studies considering skin status descriptors as factors; several more studies than previous reviews. Our methods follow validated practice: extracted data with the guidance of the REporting recommendations for tumour MARKer prognostic studies checklist and other methodological publications (Altman and Lyman, 1998; Altman et al., 2012; Hayden et al., 2006; McShane et al., 2005; Peat et al., 2014; Riley et al., 2003). We applied the validated Quality In Prognosis Studies tool to assess risk of bias. We also employed meta-analysis in quantitatively evaluating the strength of prognostic association of specific skin status descriptors. Finally, we rated the certainty of the evidence using the Grades of Recommendation Assessment, Development and Evaluation approach and found that the evidence for the prognostic value of most skin status descriptors remains uncertain.

This review has some limitations. Firstly we were only able to check data extraction for $20 \%$ of the included studies, which might have led to a higher risk of information extraction errors than full dual, independent data extraction (Buscemi et al., 2006). However, the low or very low-certainty of evidence in this review would probably not change even if dual extraction was undertaken. This is because (1) low quality is one of the continuing concerns with studies in the wound care field, and the same is probably the case for prognostic factor studies (Hodgson et al., 2014); (2) the prominence of exploratory studies in prognosis systematic review is probably consistent with other fields (Altman and Lyman, 1998; Tandon et al., 2010); (3) heterogeneity and publication bias are also common in prognosis reviews in other fields (Altman and Lyman, 1998; Tandon et al., 2010); and (4) the evidence has shown that meta-analysis of data extracted by a single reviewer and checked by another can often produce identical results to meta-analysis of data extracted by dual reviewers (Buscemi et al., 2006).

Secondly, contacting authors did not allow us to collect all unpublished data that might have been relevant to the review. Sensitivity analysis, where available unpublished data were removed, suggested that the results of the meta-analyses were stable when only published data were included. Therefore, failure to collect all the unpublished data might not change the findings and conclusion of this review. Thirdly, we excluded four studies that used the Waterlow skin type sub-scale (a composite of specific skin status descriptors using numerical values). Though the four studies contained individual-level data on specific skin status descriptors (e.g., non-blanchable erythema) we were not able to collect individual-level data for any meta-analysis.

Finally, though we aimed to minimise heterogeneity by analysing different skin status descriptors separately and undertaking pre-specified sub-group analyses, much unexplained heterogeneity 
remained. This could result from the common causes of heterogeneity in prognosis research, e.g. variations in settings and populations, adjustment for different sets of factors, the use of different assessment methods, and different follow-up durations (Altman and Lyman, 1998; Tandon et al., 2010). However, due to a small number of included studies, these causes were not considered in ad hoc sub-group analysis to explain heterogeneity further. This situation could be improved via the more standardised conduct of primary research, for example, by standardising the skin assessment method and only adjusting for a minimum set of clinically important factors in modelling.

\subsection{Implications for current practice and future research}

Guidelines commonly recommend considering signs of deteriorating skin status as a signal to prompt individualised pressure ulcer care plans (NICE, 2014). Currently this review suggests there is low certainty evidence that people with certain skin status (i.e., non-blanchable erythema, nonblanchable erythema in combination with other skin status) may have a higher risk of developing new pressure ulcers than those without these skin statuses. This finding supports regular skin assessment and preventive action being taken in the presence of non-blanchable erythema.

In future prognosis research, researchers should undertake the confirmatory phase of investigations, enrol sufficient participants (ensuring more than ten events per variable), and completely report the results of studies (e.g., regression coefficients) by complying with the reporting requirements for observational studies (Altman et al., 2012; von Elm et al., 2007). In addition, future research should clearly define specific skin status; and there may be work to be done in standardising and evaluating different skin assessment methods to help avoid potential skin status measurement errors. Moreover, we would repeat the call for establishing a minimum data set to inform future pressure ulcer prognostic factor research (Coleman et al., 2013). We also recommend that future research might also examine the association between skin status at defined anatomical locations and pressure ulcer development at the same location (Smith et al., 2017; Lechner et al., 2017).

Future secondary research could improve the certainty of the evidence by exploring the reasons for the high heterogeneity and obtaining complete data from individual studies; Study level meta-analysis has limitations in these reports (Riley et al., 2010) and meta-analysis of individual participant data offers a solution because the statistical analysis can adjust for the same set of covariates across studies, and avoid selective reporting of prognostic effects (Riley et al., 2010). Non-blanchable erythema is particularly highlighted in pressure ulcer guidelines, and plays an important role in developing individualised care plan (NICE, 2014). Future studies might therefore start with the investigation of the prognostic value of non-blanchable erythema through individual participant data meta-analysis. 


\section{Conclusions}

Low-certainty evidence suggests that more people with non-blanchable erythema might develop a new pressure ulcer than those without non-blanchable erythema. There is very low-certainty evidence on the prognostic effects of other skin status (e.g., current pressure ulcers, a history of pressure ulcers). In contrast with previous reviews, this review uses recently established prognosis research methods to synthesise the evidence for specific skin status descriptors being predictors of future pressure ulceration. Nevertheless the application of new methods cannot resolve all the limitations of the evidence base. Given that most studies are exploratory rather than confirmatory, more high quality confirmatory studies are required. Furthermore the incomplete reporting of non-significant results in some studies challenges a full evaluation of skin status using aggregate data meta-analysis, and metaanalysis of individual participant data for non-blanchable erythema is required. 


\section{Acknowledgement}

This research was funded by the President's Doctoral Scholar award of the University of Manchester (CS) and supported by the NIHR Manchester Biomedical Research Centre. The funder had no role in study design, data collection and analysis, decision to publish, or preparation of the manuscript.

The authors would like to acknowledge the contribution of Ross Atkinson, Maggie Westby, and Gillian Norman who conducted independent screening of search results for eligible studies, as well as Zhenmi Liu who carried out independent study selection and independent data checking. We would also like to acknowledge original authors who supplied additional data for clarifying the results reported in their study publications. 


\section{References}

Allegretti, A.L.C., 2008. Factors associated with clinical decisions and pressure ulcer development in long term care residents. Ph.D., University of Pittsburgh.

Allman, R.M., Goode, P.S., Patrick, M.M., Burst, N., Bartolucci, A.A., 1995. Pressure ulcer risk factors among hospitalized patients with activity limitation. JAMA 273(11), 865-70.

Altman, D.G., Lyman, G.H., 1998. Methodological challenges in the evaluation of prognostic factors in breast cancer. Breast Cancer Research and Treatment 52, 289-303.

Altman, D.G., 2001. Systematic reviews of evaluations of prognostic variables. BMJ 323, 224-228.

Altman, D.G., Bland, J.M., 2003. Interaction revisited: the difference between two estimates. BMJ 326, 219.

Altman, D.G., McShane, L.M., Sauerbrei, W., Taube, S.E., 2012. Reporting Recommendations for Tumor Marker Prognostic Studies (REMARK): Explanation and Elaboration. PLOS Medicine 9, e1001216.

Anthony, D., Clark, M., Dallender, J., 2000. An optimization of the Waterlow score using regression and artificial neural networks. Clinical Rehabilitation 14(1), 102-9.

Anthony, D., Reynolds, T., Russell, L., 2003. A regression analysis of the Waterlow score in pressure ulcer risk assessment. Clinical Rehabilitation 17(2), 216-23.

Baumgarten, M., Margolis, D., van Doorn, C., Gruber-Baldini, A.L., Hebel, J.R., Zimmerman, S., Magaziner, J., 2004. Black/White differences in pressure ulcer incidence in nursing home residents. Journal of the American Geriatrics Society 52(8), 1293-8.

Baumgarten, M., Margolis, D.J., Localio, A.R., Kagan, S.H., Lowe, R.A., Kinosian, B., Holmes, J.H., Abbuhl, S.B., Kavesh, W., Ruffin, A., 2006. Pressure ulcers among elderly patients early in the hospital stay. Journals of Gerontology Series A-Biological Sciences \& Medical Sciences 61(7), $749-54$.

Baumgarten, M., Margolis, D.J., Orwig, D.L., Shardell, M.D., Hawkes, W.G., Langenberg, P., Palmer, M.H., Jones, P.S., McArdle, P.F., Sterling, R., Kinosian, B.P., Rich, S.E., Sowinski, J., Magaziner, J., 2009. Pressure ulcers in elderly patients with hip fracture across the continuum of care. Journal of the American Geriatrics Society 57(5), 863-70. 
Beeckman, D., Van Lancker, A., Van Hecke, A., Verhaeghe, S., 2014. A systematic review and metaanalysis of incontinence-associated dermatitis, incontinence, and moisture as risk factors for pressure ulcer development. Research in Nursing \& Health 37, 204-218.

Beeckman, D.; Global IAD Expert Panel, 2015. Incontinence-associated dermatitis: moving prevention forward.

Bergquist-Beringer, S., Gajewski, B.J., 2011. Outcome and assessment information set data that predict pressure ulcer development in older adult home health patients. Advances in Skin \& Wound Care 24(9), 404-14.

Berlowitz, D.R., Ash, A.S., Brandeis, G.H., Brand, H.K., Halpern, J.L., Moskowitz, M.A., 1996. Rating long-term care facilities on pressure ulcer development: importance of case-mix adjustment. Annals of Internal Medicine 124(6), 557-63.

Berlowitz, D.R., Brandeis, G.H., Morris, J.N., Ash, A.S., Anderson, J.J., Kader, B., Moskowitz, M.A., 2001a. Deriving a risk-adjustment model for pressure ulcer development using the Minimum Data Set. Journal of the American Geriatrics Society 49(7), 866-71.

Berlowitz, D.R., Brandeis, G.H., Anderson, J.J., Ash, A.S., Kader, B., Morris, J.N., Moskowitz, M.A., 2001b. Evaluation of a risk-adjustment model for pressure ulcer development using the Minimum Data Set. Journal of the American Geriatrics Society 49(7), 872-6.

Borenstein, M., Hedges, L.V., Higgins, J.P.T., Rothstein, H.R., 2009. Introduction to Meta-Analysis. West Sussex: John Wiley \& Sons, Ltd.

Buscemi, N., Hartling, L., Vandermeer, B., Tjosvold, L., Klassen, T.P., 2006. Single data extraction generated more errors than double data extraction in systematic reviews. Journal of Clinical Epidemiology 59, 697-703.

Coleman, S., Gorecki, C., Nelson, E.A., Closs, S.J., Defloor, T., Halfens, R., Farrin, A., Brown, J., Schoonhoven, L., Nixon, J., 2013. Patient risk factors for pressure ulcer development: systematic review. International Journal of Nursing Studies 50, 974-1003.

Compton, F., Hoffmann, F., Hortig, T., Strauss, M., Frey, J., Zidek, W., Schafer, J.H., 2008. Pressure ulcer predictors in ICU patients: nursing skin assessment versus objective parameters.[Erratum appears in J Wound Care. 2008 Nov;17(11):493]. Journal of Wound Care 17(10), 417-20, 422-4.

Cullum, N., Buckley, H., Dumville, J., Hall, J., Lamb, K., Madden, M., Morley, R., O’Meara, S., Goncalves, P.S., Soares, M., Stubbs, N., 2016. Wounds research for patient benefit: a 5-year 
programme of research, Programme Grants for Applied Research. NIHR Journals Library, Southampton (UK).

de Groot, S., Dallmeijer, A.J., Post, M.W., van Asbeck, F.W., Nene, A.V., Angenot, E.L., van der Woude, L.H., 2006. Demographics of the Dutch multicenter prospective cohort study 'Restoration of mobility in spinal cord injury rehabilitation'. Spinal Cord 44(11), 668-75.

de Souza, D.M., Santos, V.L., 2007. Risk factors for pressure ulcer development in institutionalized elderly. Revista Latino-Americana de Enfermagem 15(5), 958-64.

Defloor, T., Grypdonck, M.F., 2005. Pressure ulcers: validation of two risk assessment scales. Journal of Clinical Nursing 14(3), 373-82.

DeJong, G., Ching-Hui, J.H., Brown, P., Smout, R.J., Horn, S.D., Ballard, P., Bouchard, T., 2014. Factors Associated with Pressure Ulcer Risk in Spinal Cord Injury Rehabilitation. American Journal of Physical Medicine \& Rehabilitation 93(11), 971-986.

Demarré, L., Beeckman, D., Vanderwee, K., Defloor, T., Grypdonck, M., Verhaeghe, S., 2012. Multistage versus single-stage inflation and deflation cycle for alternating low pressure air mattresses to prevent pressure ulcers in hospitalised patients: a randomised-controlled clinical trial. International Journal of Nursing Studies 49(4), 416-26.

Demarre, L., Verhaeghe, S., Van Hecke, A., Clays, E., Grypdonck, M., Beeckman, D., 2015. Factors predicting the development of pressure ulcers in an at-risk population who receive standardized preventive care: secondary analyses of a multicentre randomised controlled trial. Journal of Advanced Nursing 71(2), 391-403.

Geersing, G.J., Bouwmeester, W., Zuithoff, P., Spijker, R., Leeflang, M., Moons, K., 2012. Search filters for finding prognostic and diagnostic prediction studies in Medline to enhance systematic reviews. PLoS One 7(2):e32844

Gélis, A., Dupeyron, A., Legros, P., Benaïm, C., Pelissier, J., Fattal, C., 2009. Pressure ulcer risk factors in persons with SCI: Part I: Acute and rehabilitation stages. Spinal Cord 47, 99-107.

Gordon, M.D., 2009. Psychometric evaluation of a new pressure ulcer skin risk assessment scale for the pediatric burn patient. Ph.D., The University of Texas Medical Branch Graduate School of Biomedical Sciences.

Ham, W., Schoonhoven, L., Schuurmans, M.J., Leenen, L.P.H., 2014. Pressure ulcers from spinal immobilization in trauma patients: a systematic review. Journal of Trauma and Acute Care Surgery $76,1131-1141$. 
Hayden, J.A., Côté, P., Bombardier, C., 2006. Evaluation of the Quality of Prognosis Studies in Systematic Reviews. Annals of Internal Medicine 144, 427-437.

Hayden, J.A., Côté, P., Steenstra, I.A., Bombardier, C., QUIPS-LBP Working Group, 2008. Identifying phases of investigation helps planning, appraising, and applying the results of explanatory prognosis studies. Journal of Clinical Epidemiology 61, 552-560.

Hayden, J.A., van der Windt, D.A., Cartwright, J.L., Côté, P., Bombardier, C., 2013. Assessing bias in studies of prognostic factors. Annals of Internal Medicine 158, 280-286.

Higgins, J.P.T., Thompson, S.G., Deeks, J.J., Altman, D.G., 2003. Measuring inconsistency in metaanalyses. BMJ 327, 557-560.

Higgins JPT, Green S (editors). Cochrane Handbook for Systematic Reviews of Interventions Version 5.1.0 [updated March 2011]. The Cochrane Collaboration, 2011. Available from www.handbook.cochrane.org.

Hodgson, R., Allen, R., Broderick, E., Bland, J.M., Dumville, J.C., Ashby, R., Bell-Syer, S., Foxlee, R., Hall, J., Lamb, K., Madden, M., O’Meara, S., Stubbs, N., Cullum, N., 2014. Funding source and the quality of reports of chronic wounds trials: 2004 to 2011. Trials 15, 19.

Horn, S.D., Bender, S.A., Bergstrom, N., Cook, A.S., Ferguson, M.L., Rimmasch, H.L., Sharkey, S.S., Smout, R.J., Taler, G.A., Voss, A.C., 2002. Description of the National Pressure Ulcer Long-Term Care Study. Journal of the American Geriatrics Society 50(11), 1816-25.

Horn, S.D., Bender, S.A., Ferguson, M.L., Smout, R.J., Bergstrom, N., Taler, G., Cook, A.S., Sharkey, S.S., Voss, A.C., 2004. The National Pressure Ulcer Long-Term Care Study: pressure ulcer development in long-term care residents. Journal of the American Geriatrics Society 52(3), $359-67$.

Huguet, A., Hayden, J.A., Stinson, J., McGrath, P.J., Chambers, C.T., Tougas, M.E., Wozney, L., 2013. Judging the quality of evidence in reviews of prognostic factor research: adapting the GRADE framework. Systematic Reviews 2, 71.

Ingui, B.J., Rogers, M.A., 2001. Searching for clinical prediction rules in MEDLINE. Journal of the American Medical Informatics Association 8, 391-397.

Ioannidis, J.P.A., Patsopoulos, N.A., Rothstein, H.R., 2008. Reasons or excuses for avoiding metaanalysis in forest plots. BMJ 336, 1413-1415.

Kroll, T., Neri, M.T., Ho, P., 2007. Secondary conditions in spinal cord injury: results from a prospective survey. Disability \& Rehabilitation 29(15), 1229-1237. 
Liu, P., He, W., Chen, H.-L., 2012. Diabetes mellitus as a risk factor for surgery-related pressure ulcers: a meta-analysis. Journal of Wound Ostomy \& Continence Nursing 39, 495-499.

Magaziner, J., German, P., Zimmerman, S.I., Hebel, J.R., Burton, L., Gruber-Baldini, A.L., May, C., Kittner, S., 2000. The prevalence of dementia in a statewide sample of new nursing home admissions aged 65 and older: diagnosis by expert panel. Epidemiology of Dementia in Nursing Homes Research Group. Gerontologist 40(6), 663-72.

Man, S.P., Au-Yeung, T.W., 2013. Hypotension is a risk factor for new pressure ulcer occurrence in older patients after admission to an acute hospital. Journal of the American Medical Directors Association 14(8), 627.e1-5.

Marin, J., Nixon, J., Gorecki, C., 2013. A systematic review of risk factors for the development and recurrence of pressure ulcers in people with spinal cord injuries. Spinal Cord 51, 522-527.

McInnes, E., Jammali-Blasi, A., Bell-Syer, S.E., Dumville, J.C., Middleton, V., Cullum, N., 2015. Support surfaces for pressure ulcer prevention. The Cochrane Database of Systematic Reviews 9, CD001735.

McShane, L.M., Altman, D.G., Sauerbrei, W., Taube, S.E., Gion, M., Clark, G.M., 2005. REporting recommendations for tumour MARKer prognostic studies (REMARK). Br J Cancer 93, 387391.

Mehio-Sibai, A., Feinleib, M., Sibai, T.A., Armenian, H.K., 2005. A positive or a negative confounding variable? A simple teaching aid for clinicians and students. Annals of Epidemiology 15, 421-423. https://doi.org/10.1016/j.annepidem.2004.10.004

Michel, J.M., Willebois, S., Ribinik, P., Barrois, B., Colin, D., Passadori, Y., 2012. As of 2012, what are the key predictive risk factors for pressure ulcers? Developing French guidelines for clinical practice. Annals of Physical and Rehabilitation Medicine 55, 454-465.

Molon, J.N.D., Estrella, E.P., 2011. Pressure ulcer incidence and risk factors among hospitalized orthopedic patients: results of a prospective cohort study. Ostomy Wound Management 57(10), 64-69.

National Pressure Ulcer Advisory Panel, European Pressure Ulcer Advisory Panel and Pan Pacific Pressure Injury Alliance (NPUAP/EPUAP/PPPIA). Prevention and Treatment of Pressure Ulcers: Quick Reference Guide. Emily Haesler (Ed.). Cambridge Media: Osborne Park, Western Australia; 2014. 
National Institute for Health and Care Excellence (NICE), 2014. Pressure ulcers: prevention and management (Clinical guideline No. CG179). http $/ /$ guidance.nice.org.uk/CG179

Nixon, J., Cranny, G., Iglesias, C., Nelson, E.A., Hawkins, K., Phillips, A., Torgerson, D., Mason, S., Cullum, N., 2006a. Randomised, controlled trial of alternating pressure mattresses compared with alternating pressure overlays for the prevention of pressure ulcers: PRESSURE (pressure relieving support surfaces) trial. BMJ, 332(7555), 1413.

Nixon, J., Nelson, E.A., Cranny, G., Iglesias, C.P., Hawkins, K., Cullum, N.A., Phillips, A., Spilsbury, K., Torgerson, D.J.. Mason, S., PRESSURE Trial Group., 2006b. Pressure relieving support surfaces: a randomised evaluation. Health Technology Assessment 10(22), iii-iv, ix-x, 1163.

Nixon, J., Cranny, G., Bond, S., 2007. Skin alterations of intact skin and risk factors associated with pressure ulcer development in surgical patients: a cohort study. International Journal of Nursing Studies 44(5), 655-63.

Nixon, J., Nelson, E.A., Rutherford, C., Coleman, S., Muir, D., Keen, J., McCabe, C., Dealey, C., Briggs, M., Brown, S., Collinson, M., Hulme, C.T., Meads, D.M., McGinnis, E., Patterson, M., Czoski-Murray, C., Pinkney, L., Smith, I.L., Stevenson, R., Stubbs, N., Wilson, L., Brown, J.M., 2015. Pressure UlceR Programme Of reSEarch (PURPOSE): using mixed methods (systematic reviews, prospective cohort, case study, consensus and psychometrics) to identify patient and organisational risk, develop a risk assessment tool and patient-reported outcome Quality of Life and Health Utility measures. Programme Grants for Applied Research, 3(6).

Page, K.N., Barker, A.L., Kamar, J., 2011. Development and validation of a pressure ulcer risk assessment tool for acute hospital patients. Wound Repair \& Regeneration 19(1), 31-7.

Papanikolaou, P., Clark, M., Lyne, P.A., 2002. Improving the accuracy of pressure ulcer risk calculators: some preliminary evidence. International Journal of Nursing Studies 39(2), 187-94.

Parmar, M.K., Torri, V., Stewart, L., 1998. Extracting summary statistics to perform meta-analyses of the published literature for survival endpoints. Statistics in Medicine 17, 2815-2834.

Peat, G., Riley, R.D., Croft, P., Morley, K.I., Kyzas, P.A., Moons, K.G.M., Perel, P., Steyerberg, E.W., Schroter, S., Altman, D.G., Hemingway, H., PROGRESS Group, 2014. Improving the transparency of prognosis research: the role of reporting, data sharing, registration, and protocols. PLoS Medicine 11, e1001671. 
Perneger, T.V., Rae, A.C., Gaspoz, J.M., Borst, F., Vitek, O., Heliot, C., 2002. Screening for pressure ulcer risk in an acute care hospital: development of a brief bedside scale. Journal of Clinical Epidemiology 55(5), 498-504.

Peters, J.L., Sutton, A.J., Jones, D.R., Abrams, K.R., Rushton, L., 2008. Contour-enhanced metaanalysis funnel plots help distinguish publication bias from other causes of asymmetry. Journal of Clinical Epidemiology 61, 991-996.

Poss, J., Murphy, K.M., Woodbury, M.G., Orsted, H., Stevenson, K., Williams, G., Macalpine, S., Curtin-Telegdi, N., Hirdes, J.P., 2010. Development of the interRAI Pressure Ulcer Risk Scale (PURS) for use in long-term care and home care settings. BMC Geriatrics 10, 67.

Primiano, M., Friend, M., McClure, C., Nardi, S., Fix, L., Schafer, M., Savochka, K., McNett, M., 2011. Pressure ulcer prevalence and risk factors during prolonged surgical procedures. AORN Journal 94(6), 555-66.

Reed, R.L., Hepburn, K., Adelson, R., Center, B., McKnight, P., 2003. Low serum albumin levels, confusion, and fecal incontinence: are these risk factors for pressure ulcers in mobility-impaired hospitalized adults? Gerontology 49(4), 255-259.

Reenalda, J., Jannink, M., Nederhand, M., IJzerman, M., 2009. Clinical use of interface pressure to predict pressure ulcer development: a systematic review. Assistive Technology 21, 76-85.

Rich, S.E., Margolis, D., Shardell, M., Hawkes, W.G., Miller, R.R., Amr, S., Baumgarten, M., 2011. Frequent manual repositioning and incidence of pressure ulcers among bed-bound elderly hip fracture patients. Wound Repair \& Regeneration 19(1), 10-18.

Riley, R.D., Ridley, G., Williams, K., Altman, D.G., Hayden, J., de Vet, H.C.W., 2007. Prognosis research: toward evidence-based results and a Cochrane methods group. Journal of Clinical Epidemiology 60, 863-865; author reply 865-866.

Riley, R.D., Abrams, K.R., Sutton, A.J., Lambert, P.C., Jones, D.R., Heney, D., Burchill, S.A., 2003. Reporting of prognostic markers: current problems and development of guidelines for evidencebased practice in the future. British Journal of Cancer 88, 1191-1198.

Riley, R.D., Lambert, P.C., Abo-Zaid, G., 2010. Meta-analysis of individual participant data: rationale, conduct, and reporting. BMJ 340, c221.

Scheel-Sailer, A., Wyss, A., Boldt, C., Post, M. W., Lay, V., 2013. Prevalence, location, grade of pressure ulcers and association with specific patient characteristics in adult spinal cord injury patients during the hospital stay: a prospective cohort study. Spinal Cord 51(11), 828-33. 
Schnelle, J.F., Adamson, G.M., Cruise, P.A., al-Samarrai, N., Sarbaugh, F.C., Uman, G., Ouslander, J.G., 1997. Skin disorders and moisture in incontinent nursing home residents: intervention implications. Journal of the American Geriatrics Society 45(10), 1182-8.

Schoonhoven, L., Van Kol, E., Buskens, E., Van Achterberg, T., 2005. Pressure ulcers: development and validation of a prediction rule. $16^{\text {th }}$ International Nursing Research Congress, Hawaii Big Island.

Schoonhoven, L., Grobbee, D.E., Donders, A.R.T., Algra, A., Grypdonck, M.H., Bousema, M.T., Schrijvers, A.J.P., Buskens, E., 2006. Prediction of pressure ulcer development in hospitalized patients: a tool for risk assessment. Quality \& Safety in Health Care 65-70.

Schoonhoven, L., Bousema, M.T., Buskens, E., prePURSE-study group, 2007. The prevalence and incidence of pressure ulcers in hospitalised patients in the Netherlands: a prospective inception cohort study. International Journal of Nursing Studies 44(6), 927-35.

Smith, I.L., Brown, S., McGinnis, E., Briggs, M., Coleman, S., Dealey, C., Muir, D., Nelson, E.A., Stevenson, R., Stubbs, N., Wilson, L., Brown, J.M., Nixon, J., 2017. Exploring the role of pain as an early predictor of category 2 pressure ulcers: a prospective cohort study. BMJ Open 7(1), $\mathrm{e} 013623$.

Steyerberg, E.W., Moons, K.G.M., van der Windt, D.A., Hayden, J.A., Perel, P., Schroter, S., Riley, R.D., Hemingway, H., Altman, D.G., PROGRESS Group, 2013. Prognosis Research Strategy (PROGRESS) 3: prognostic model research. PLoS Medicine 10, e1001381.

Stordeur, S., Laurent, S., D'Hoore, W., 1998. The importance of repeated risk assessment for pressure sores in cardiovascular surgery. Journal of Cardiovascular Surgery 39(3), 343-9.

Stroup, D.F., Berlin, J.A., Morton, S.C., Olkin, I., Williamson, G.D., Rennie, D., Moher, D., Becker, B.J., Sipe, T.A., Thacker, S.B., (MOOSE) Group, for the M.O.O.S. in E., 2000. Meta-analysis of Observational Studies in Epidemiology: A Proposal for Reporting. JAMA 283, 2008-2012.

Sun, X., Briel, M., Walter, S.D., Guyatt, G.H., 2010. Is a subgroup effect believable? Updating criteria to evaluate the credibility of subgroup analyses. BMJ 340, c117.

Takahashi, P.Y., Chandra, A., Cha, S.S., 2011. Risk factors for pressure ulceration in an older community-dwelling population. Advances in Skin \& Wound Care 24(2), 72-7.

Tandon, S., Tudur-Smith, C., Riley, R.D., Boyd, M.T., Jones, T.M., 2010. A Systematic Review of p53 as a Prognostic Factor of Survival in Squamous Cell Carcinoma of the Four Main Anatomical Subsites of the Head and Neck. Cancer Epidemiol Biomarkers Prev 19, 574-587. 
Tsai, Y.C., Lin, S.Y., Liu, Y., Wang, R.H., 2012. Factors related to the development of pressure ulcers among new recipients of home care services in Taiwan: a questionnaire study. International Journal of Nursing Studies 49(11), 1383-90.

Vanderwee, K., Grypdonck, M.H.F., Defloor, T., 2005. Effectiveness of an alternating pressure air mattress for the prevention of pressure ulcers. Age \& Ageing 34(3), 261-267.

Vanderwee, K., Grypdonck, M., Defloor, T., 2007. Non-blanchable erythema as an indicator for the need for pressure ulcer prevention: a randomized-controlled trial. Journal of Clinical Nursing 16, $325-335$.

van der Wielen, H., Post, M.W., Lay, V., Gläsche, K. Scheel-Sailer, A., 2016. Hospital-acquired pressure ulcers in spinal cord injured patients: time to occur, time until closure and risk factors. Spinal Cord 54(9), 726-731.

Verschueren, J.H., Post, M.W., de Groot, S., van der Woude, L.H., van Asbeck, F.W., Rol, M., 2011. Occurrence and predictors of pressure ulcers during primary in-patient spinal cord injury rehabilitation. Spinal Cord 49(1), 106-12.

von Elm, E., Altman, D.G., Egger, M., Pocock, S.J., Gøtzsche, P.C., Vandenbroucke, J.P., STROBE Initiative, 2007. The Strengthening the Reporting of Observational Studies in Epidemiology (STROBE) statement: guidelines for reporting observational studies. Lancet 370, 1453-1457.

Walker-Dilks, C., Wilczynski, N.L., Haynes, R.B., 2008. Cumulative Index to Nursing and Allied Health Literature search strategies for identifying methodologically sound causation and prognosis studies . Applied Nursing Research 21(2):98-103.

Webster, J., Coleman, K., Mudge, A., Marquart, L., Gardner, G., Stankiewicz, M., Kirby, J., Vellacott, C., Horton-Breshears, M., McClymont, A., 2011. Pressure ulcers: effectiveness of risk-assessment tools. A randomised controlled trial (the ULCER trial). BMJ Quality \& Safety 20(4), 297-306.

Wilczynski, N.L., Haynes, R.B., 2004. Developing optimal search strategies for detecting clinically sound prognostic studies in MEDLINE: an analytic survey. BMC Medicine 2:23. 